\title{
Superfícies oclusais metálicas em reabilitação oral
}

\author{
Prof. Ézio Teseo Mainieri*** \\ Dra. Elken Gomes Rivaldo** \\ Dr. Antonio Felipe Costa da Rosa*
}

\section{RESUMO}

Técnicas que permitem o desenvolvimento de apuradas superfícies oclusais em prótese parcial, com estética, sảo descritas. A oclusão desenvolvida permite harmonia oclusal com próteses parciais removíveis a qual nāo seria possível executar com dentes de estoque ou dentes de estoque com superfícies oclusais adaptadas.

\section{SUMMARY}

Techniques that allow the development of, on esthetic, accurate metal oclusal surfaces for a removable partial denture are described. The occlusion developed allows an occlusal harmony with the removable partial denture that is not possible with stock denture teeth or metal occlusal surfaces developed with stock denture teeth

\section{DESCRITORES}

\author{
PRÓTESE PARCIAL REMOVÍVEL • FUNDIÇĀO • ATM
}

Existem casos em reabilitação oral onde os dentes de porcelana são contra-indicados, e onde os de resina acrílica são indicados erroneamente. Também existem situaçōes em que os dentes săo modificados para obter-se alternativas aceitáveis com dentes de estoque em porcelana ou resina acrílica. Estas modificaçōes, na forma dos dentes posteriores săo representadas por:

- faixas metálicas

- amálgamas oclusais

- superfícies oclusais metálicas

- barras de corte

Quando realizamos um trabalho protético com superfícies oclusais metálicas, estas contribuem para aumentar o sucesso clínico, sendo indicadas quando:

$\left.1^{\circ}\right)$ realizamos uma dentadura completa, onde o antagonista foi reconstruído com superfícies oclusais em metal.

$2^{\circ}$ ) construimos uma dentadura completa ou aparelho parcial removível onde existem consideráveis modificaçōes dos dentes do aparelho, para que as superfícies oclusais $\theta 0$ corpo fiquem em harmonia, usando a técnica da funçăo gera- da de padrōes. (F.G.P.).

$3^{\circ}$ ) quando um padrão especial de encerramento é finalizado em um articulador totalmente ajustável, para o desenvolvimento de uma oclusăo funcional.

O problema de ocluir vários tipos de dentes artificiais contra dentes naturais é conhecido por todos os cirurgiōes dentistas. Dentes de porcelana tendem a fraturar, especialmente as cúspides palatinas superiores e as cúspides vestibulares dos dentes inferiores (cúspides de trabalho). $O$ desgaste dos dentes de porcelana para pacientes com uma pequena dimensāo vertical, enfraquecem os mesmos, provocando fraturas excessivas.

Quanto aos dentes de resina, desgastam-se rapidamente com o uso, causando alteraçōes na oclusão cêntrica, perda da dimensăo vertical de oclusăo, frequentemente distúrbios na Atm e extrusāo dos dentes antagonistas. Estas dificuidades não ocorrem utilizando superfícies oclusais de metal, uma vez que elas sāo ideais para pacientes com pequena dimensăo vertical, e na construçăo de prótese antagonista a dentes naturais, visto que ao utilizar dentes de porcelana, em próteses totais e parciais, os antagonistas naturais ou restaurados com trabalhos protéticos com superfícies oclusais metálicas sofrem fraturas, ao mesmo tempo que, utilizando-se dentes de resina acrílica, estes sofrerão desgaste, causando perda de dimensăo vertical e da funçăo.

Esta técnica da construçäo de apareIhos parciais removíveis com superfícies oclusais metálicas que ocluem contra dentes naturais, próteses fixas, e removíveis e dentaduras completas, é a situação ideal, pois o conforto e a eficiência mastigatória säo os fatores que devem receber maior atençāo dos profissionais, quando da restauração de áreas edêndulas, uma vez que estes são os dois objetivos mais importantes em trabalhos protéticos.

*** Professor Adjunto das disciplinas de Prótese Parcial I e II - UFRGS. Coordenador do Curso de Pós-Graduaçāo em Prótese Dental - UFRGS.

** Aluna do Curso de Pós-Graduação em Prótese Dental - UFRGS.

* C.D. Pós-Graduado em Dentística Restauradora - UFRGS. 


\section{Técnica da confecção de aparelhos protéticos com superfícies oclusais metálicas}

Dentes para prótese com superfícies oclusais metálicas, devem ser fabricados para adaptar-se às exigências das superfícies oclusais dos dentes antagonistas, isto é, especialmente verdadeiro na maioria das próteses parciais ou em dentaduras completas antagonista, a dentaduras parciais. No entanto, isto não é verdadeiramente necessário para pacientes classe I de Kennedy superior e inferior. Na maioria das próteses removíveis, nós devemos ajustar a oclusão nos dentes de resina acrílica, para depois transformá-los em metal. A utilizaçāo de superfícies oclusais metálicas pré-fabricadas torna o ajuste mais difícil, devido a variação morfológica que estas apresentam. Os procedimentos usuais na construçăo das próteses não săo alterados em nenhum outro aspecto. Os aparelhos protéticos são confeccionados na forma habitual, utilizada na técnica para dentes em resina acrílica. Qualquer tipo de oclusäo ou planejamento oclusal podem ser utilizados. Qualquer grau de inclinaçăo cúspidea escolhido para o paciente pode ser utilizado, desde que os dentes sejam de resina acrílica.

Os aparelhos protéticos são confeccionados da maneira usual, mas antes de serem removidas dos modelos, elas são remontadas no articulador onde realizamos um ajuste oclusal.

Então os aparelhos protéticos são finalizados, polidos e entregues ao paciente, săo usados por um período de três a quatro semanas. Durante este período, os ajustes das superfícies oclusais são realizados. A confecção das superfícies oclusais metálicas poderá entāo ser iniciada.

\subsection{Preparação dos Modelos}

Realizam-se impressōes de alginato dos arcos dentários com as próteses colocadas em posiçăo. Vaza-se gesso pedra sobre o conjunto moldagem e o aparelho protético assentados cuidadosamente sobre o modelo de gesso. Cuidados devem ser tomados para evitar-se o preenchimento das retençōes com gesso.

Neste momento os modelos devem ser montados em um articulador semi-ajustável.

\subsection{Preparação dos dentes para receber oclusais metalizadas}

Uma preparaçāo assemelhando-se a uma coroa $3 / 4$ modificada com caneletas oclusais é realizada em cada dente.

Aproximadamente $1 \mathrm{~mm}$ de resina acrílica é removida da superfície oclusal por vestibular e $2 \mathrm{~mm}$ por palatino. Preparaçōes semelhantes sảo realizadas para os dentes inferiores com a remoção de $1,5 \mathrm{~mm}$ de resina da superfície oclusal por vestibular e lingual. Uma broca $n^{\circ} 51$, haste longa de aço é usada para esta preparaçāo.

Uma espessura suficiente de resina deve ser removida dos dentes a fim de prover espaço adequado para a confecçāo das superfícies oclusais de metal.

Um pequeno disco de carburundum é usado para confeccionar um sulco contínuo no sentido antero-posterior no sulco central de todas as superfícies oclusais dos dentes. O sulco deve ter em torno de $3 \mathrm{~mm}$ de largura por $3 \mathrm{~mm}$ de profundidade. As áreas de contato nas faces mesiais dos $1^{\circ} \mathrm{PM}$ e faces distais dos $2^{\circ} \mathrm{M}$ devem permanecerem intactas. Com uma broca $n^{\circ} 103$, um orifício é cuidadosamente realizado a uma profundidade de $2 \mathrm{~mm}$ no centro de cada dente no fundo do sulco previamente realizado. Todas as superfícies preparadas serāo polidas com uma roda de borracha abrasiva.

\subsection{Os padrōes em cera}

Os dentes preparados e o modelo antagonista devem ser isolados previamente à confecção dos padrōes de cera. A cera para incrustraçōes é colocada dentro das preparaçōes dos dentes do aparelho protético. Então as próteses são posicionadas firmemente nos modelos e 0 articulador é fechado.

Desta forma, os padrōes de cera sāo confeccionados a partir da própria oclusäo do paciente, constituindo-se pois, na chamada técnica do padrăo gerado; que implica em movimentaçōes cêntricas (oclusão e relação cêntrica) e excêntricas (lateralidade direita, esquerda e protusảo).

Os modelos são removidos e o excesso de cera eliminado com um instrumento afiado. Os padrōes poderāo entāo ser removidos das preparaçōes numa peça única por quadrante, utilizando-se, um jato de ar direcionado sob as margens.

\subsection{Fundição}

Obtidos os padrōes de cera ou acrílico Duralay os sopnes são conectados aos padrōes de cera.

Os padrōes sāo incluídos, fundidos, usinados e colocados sobre os dentes preparados do aparelho.

O metal a ser usado pode influir de acordo com o poder aquisitivo do paciente; em metais nāo-nobres (níquel-cromo, cobre-alumínio), metais semi-nobres (prata-paládio) e até mesmo nobres (ou ro+platina + paládio)

\subsection{Cimentação}

As incrustraçōes sảo polidas com discos de lixa médios e finos nas margens e discos apropriados nas faces oclusais.
Neste momento, os sulcos são acentuados com brocas de acabamento fino. Com um disco de carburundum são feitos sulcos nas áreas retentivas das oclusais metalizadas. Retençōes sảo cuidadosamente realizadas sobre as superfícies preparadas dos dentes de resina acrílica. Cada orifício anteriormente realizado deverá ser estendido completamente através da base do aparelho, para que - excesso de resina autopolimerizável usado na cimentação possa ser expelido.

Isola-se o resto do aparelho e as oclusais metalizadas são cimentadas com resina acrílica de rápida polimerização. Após o endurecimento da resina, o excesso é removido das demais partes do aparelho e das margens das superfícies oclusais de metal. As próteses são polidas e entregues ao paciente para serem usadas por uma semana. Depois disso, os eventuais contatos deflectivos, marcados no metal deveräo ser reexaminados e balanceados.

\section{Superfícies oclusais metálicas em dentes de porcelana}

A técnica descrita anteriormente pode variar se utilizada para dentes posteriores de porcelana, apesar de nossa reserva em relação ao seu uso.

A principal diferença entre utilizar dentes de resina acrílica e dentes de porcelana é a dificuldade de preparar estes últimos para receberem as faces oclusais de metal. A preparaçāo sob dentes de porcelana deve ser realizada individualmente e devem ser feitas antes da confecçăo do trabalho protético final. É muito complexo e consome maior tempo, năo permitindo ajustes posteriores sobre as oclusais metalizadas

\section{Técnica da confecção de superfícies oclusais com dentes pré-fabricados}

Os dentes pré-fabricados sảo construídos em blocos por quadrantes para os quatro dentes posteriores. Os padrōes oclusais metálicos sāo fundidos com metal de média dureza. Os padrōes originais são esculpidos segundo a dimensão técnica preconizada por Charles Stuart. Em sua confecçāo, as incrustraçōes sāo preparadas e finalizadas e os dentes de resina acrílica sāo processadas nas unidades metálicas em moldes impressos separadamente. As unidades dos quadrantes são $30 \mathrm{~mm}$ mais compridas, o único tamanho disponível.
R. Fac. Odontol.

Porto Alegre

V. 32

N. 1

p.12-13

JULHO

1991 


\section{Técnica simplificada para oclusais metálicas}

Nós achamos que o método aqui descrito prova rapidez, simplicidade e baixo custo na construçăo das superfícies oclusais. Depois que as próteses removíveis tenham sido colocadas, as superfícies oclusais em metal podem ser fabricadas em laboratório com o mínimo de tempo dispendido pelo dentista. Podem ser usados muitos tipos de dentes posteriores de resina e muitos tipos de anatomia oclusal.

Próteses removíveis completas ou parciais săo construídas, usando-se dentes posteriores de resina. A oclusão é ajustada e corrigida da maneira usual. $\mathrm{O}$ paciente é autorizado a usar a prótese até que 0 dentista tenha certeza que a oclusăo está correta e que a fase de ajuste está completamente finalizada.

\subsection{Construçăo de um index}

Faça um index oclusal de gesso ou acrílico dos dentes onde estão as superfícies oclusais em metal. Este index é estendido para anterior, posterior e lingualmente formando stops. Para dentaduras completas, 0 index deve ser estendido até o dente mais anteriormente colocado e posteriormente até a base de resina acrílica. Para próteses removíveis, o index de gesso deve estender-se posterior e lingualmente para prover stops adequados na base de resina acrílico.

2.2. Remova o index e ajuste-o para que cubra somente as cúspides e estenda-se dentro das fossas oclusais.

2.3. Derreta cera na incrustração do index e coloque pequenos pinos retentivos de cera, no lado de baixo dos porões das superfícies oclusais.

2.4. Inclua e funda o padrăo de cera.

2.5. Examine as incrustraçōes, quanto a bolhas e outras irregularidades que possam interferir no padrão oclusal. Ajuste as incrustraçōes de polimento, remova o mínimo de metal durante este procedimento. Isto é importante, para que nāo ocorram interferências na estabilidade do plano oclusal. Coloque as incrustraçōes dentro do index. Alivie o index superficialmente ao longo da periferia para permitir a colocaçăo de uma pequena quantidade de cimento para reter as incrustraçōes no index. O cimento é preferido à cera pegajosa, porque o líquido de acrílico tende a reagir com a cera.

2.6. Reduza as superfícies oclusais dos dentes de acrilico para que a espessura das incrustraçőes seja de $1 \mathrm{~mm}$.

2.7. Corte a cavidade através dos dentes para permitir lugar aos pinos retentivos.

2.8. Alinhe 0 index com as incrustraçōes colocadas nos dentes da prótese, tenha-os firmemente no lugar com cera pegajosa.

2.9. Espalhe resina acrílica autopolimerizável no espaço entre as incrustraçōes metálicas e a base da dentadura e espere a completa polimerização.

2.10. Adapte a resina acrílica e de polimento.

2.11. A oclusão é examinada pelo dentista que certifica-se de que não ocorreram alteraçōes. Presumido que todos os passos foram feitos corretamente, não são necessárias correçōes oclusais.

\section{Vantagens e desvantagens das superfícies oclusais metálicas}

As vantagens das superfícies oclusais de metal nas próteses usando dentes de estoque, săo:

1. Conforto e sensação natural, resultante da resiliência da resina acrílica.

2. Aumento da eficiência mastigatória.

3. Mínima perda da dimensāo vertical de oclusão.

4. Manutenção da oclusão cêntrica.

5. A superioridade em pacientes que possuem insuficiente dimensão vertical.

6. Eliminaçăo da extrusăo dos dentes naturais que pode ocorrer quando usados dentes de resina acrílica.

7. Eliminaçăo de fraturas dentárias.

As únicas desvantagens de uso das superfícies oclusais de metal é o aumento do tempo de confecção e do material utilizado, mas os resultados certamente justificam.
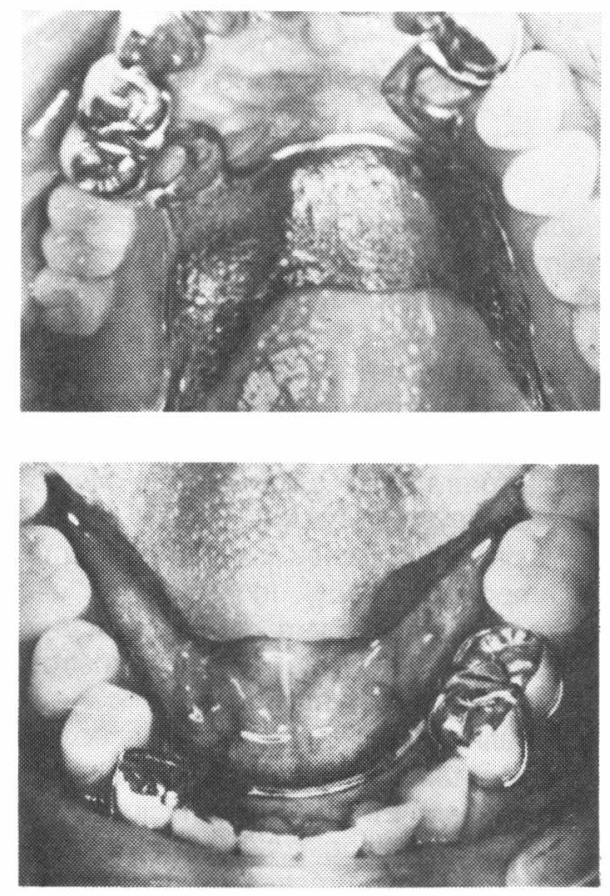
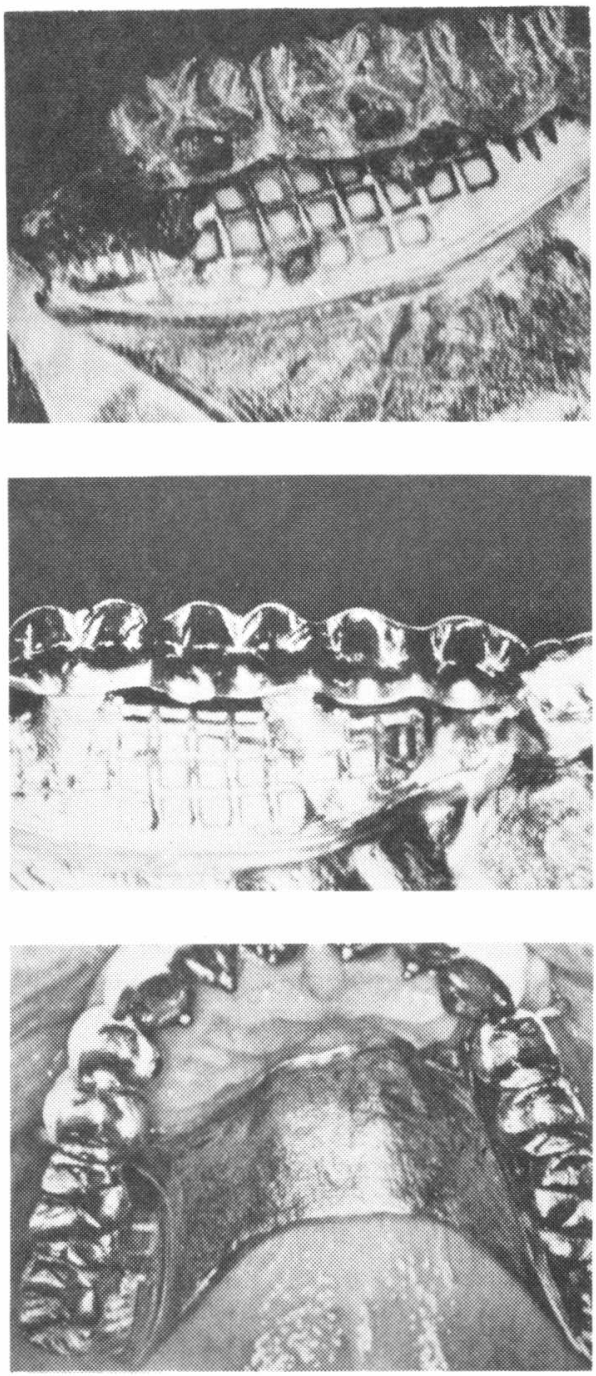

\section{REFERÊNCIAS BIBLIOGRÁFICAS}

1. BOOS, R.H. Physiologic denture technique. J. Prosthet. Dent., v. 6, p. 26-40, 1956.

2. KOEHNE, C.L.; MORROW, R.M. Construction of denture teeth with metal occlusal surfaces. J. Prosthet. Dent., v. 5, p. 29-33, 1970.

3. MANN, A.W.; PANKEY, L.D. Use of the Pankey-Mann instrument in restoring the lower posterior teeth. J. Prosthet. Dent., v. 10, p. 135-150, 1960.

4. MONGON, G.S. Applied mechanics to the teory of mandibular movements. Dent. Cosmos, v. 74, p. 1039, 1932.

5. SCHULTZ, A.W. Confort and chewing efficiency in dentures. J. Prosthet. Dent., v. 1, p. 38-48, 1951

6. WALLACE, D.H. The use of metal occlusal surfaces in complete and partial dentures. J. Prosthet. Dent., v. 14, p. 326-333, 1964. 